\title{
Incidence of common pyocin types of Pseudomonas aeruginosa from patients with cystic fibrosis and chronic airways diseases
}

\author{
M. W. TREDGETT, CATHERINE DOHERTY and J. R. W. GOVAN*
}

Department of Bacteriology, University of Edinburgh Medical School, Teviot Place, Edinburgh EH8 9AG

\begin{abstract}
Summary. We sought evidence to determine if particular strains of Pseudomonas aeruginosa have a predilection for pulmonary colonisation in patients with cystic fibrosis (CF). The incidence of common pyocin types in non-CF isolates $(74 \%)$ was similar to that noted in previous reports but differed significantly $\left(\chi^{2}=16.7\right.$, $\mathrm{p}<0.001$ ) from the incidence of $40 \%$ observed in $\mathrm{CF}$ isolates. A retrospective analysis of respiratory isolates also indicated a relatively low incidence of common pyocin types $(44 \%)$ in isolates from non-CF patients with chronic airways diseases and this incidence also differed significantly from that observed $(73 \%)$ in other respiratory isolates from patients in the same hospital. These observations suggest that a subpopulation of $\boldsymbol{P}$. aeruginosa exists which has a predilection for pulmonary colonisation in $\mathrm{CF}$ and other chronic pulmonary diseases and may assist in identification of factors affecting bacterial colonisation.
\end{abstract}

\section{Introduction}

Epidemiological studies of the association of Pseudomonas aeruginosa and chronic pulmonary colonisation in patients with cystic fibrosis (CF) are greatly helped by typing techniques which indicate the clonal relationship of individual strains. Serotyping, based on O-antigen specificity is not useful for characterisation of $P$. aeruginosa from patients with CF because of alterations in bacterial lipopolysaccharide which are characteristically observed in chronic pulmonary colonisation. ${ }^{1}$ Pyocin typing ${ }^{2,3}$ which relies on the production and detection of chromosomally determined bacteriocins, DNA probe analysis by Southern blot hybridisation with DNA fragments from the exotoxin A gene, ${ }^{4}$ and genome fingerprinting by field inversion gel electrophoresis ${ }^{5}$ have been used successfully to determine two important epidemiological factors in patients with $\mathrm{CF}^{6}$ Firstly, the majority of patients remain colonised with a single strain of $P$. aeruginos $a$ which gradually evolves to exhibit a range of phenotypic properties including mucoidy due to derepressed alginate biosynthesis, loss of $\mathrm{O}$-antigen specificity, serum sensitivity and hypersusceptibility to a range of antibiotics. Secondly, cross-infection is rare, except between siblings with $\mathrm{CF}$.

Received 3 Oct. 1989; accepted 8 Dec. 1989.

* Correspondence should be sent to Dr J. R. W. Govan.
The purpose of the present study was to address a third epidemiological consideration-to determine if a subpopulation of particular strains of $P$. aeruginosa have a predilection for chronic colonisation of $\mathrm{CF}$ patients. The rationale for the study had emerged from two sources. First, from our ongoing longitudinal studies with pyocin typing which indicated that cross-infection with the same strain was rare, and that $P$. aeruginosa isolated from patients with $C F$ appeared to have a different pyocin type distribution compared to non-CF isolates. Second, from the evidence from closely documented episodes of primary colonisation by non-mucoid $P$. aeruginosa in patients with $\mathrm{CF}$ which suggested that in environments containing multiple strains of $P$. aeruginosa some strains appeared to have enhanced ability to colonise patients. $^{7}$

\section{Materials and methods}

\section{Bacteria}

A collection of 304 non-CF isolates of $P$. aeruginosa comprised all isolates from sputum and other specimens and anatomical sites in patients treated in three Edinburgh hospitals during 1987 . The series of $69 \mathrm{CF}$ isolates of $P$. aeruginosa was from the sputum of patients attending the Edinburgh CF clinics. Subsequently, a retrospective analysis of pyocin type distribution was performed on all respiratory isolates of $P$. aeruginosa which had been isolated from non-CF patients in one hospital during the 
period 1986-1988; these isolates comprised 60 strains from patients with chronic airways diseases (CAD) and 52 from patients colonised with $P$. aeruginosa postoperatively. Isolates were identified as $P$. aeruginosa by colonial morphology and production of characteristic pigmentation of Pseudomonas Isolation Agar (Difco, 0927-01); non-pigmented isolates were identified by a positive oxidase reaction ${ }^{8}$ and with API 2ONE kits (API Laboratory Products Ltd, Basingstoke).

\section{Pyocin typing}

Pyocin typing was performed by our revised technique ${ }^{3}$ which incorporates the original type patterns designated earlier in this laboratory. Repeat specimens from the same patient were excluded, as were multiple isolations of a single epidemic strain. A $\chi^{2}$ statistical analysis was used to determine significant differences in the pyocin type distribution of the different populations; $p<0.05$ was considered to represent a statistically significant difference.

\section{Results}

Analysis of the distribution of pyocin types revealed a lower incidence of common pyocin types in patients with CF than in isolates from other patients (table I). Amongst 69 isolates from patients with $\mathrm{CF}$, only $28(40 \%)$ produced the common type patterns $1,3,5$ or 10 based on inhibition of the original set of eight indicator strains. No single pyocin type accounted for a significant proportion of the remaining 41 strains which were distributed amongst 25 pyocin types.

When the incidence of the common type patterns $1,3,5$ and 10 in CF isolates was compared with that of the non-CF isolates from the three individual hospitals, the results for hospitals 1 and $2(74 \%$ and $70 \%$ respectively) were similar to previous reports and differed significantly from the $\mathrm{CF}$ isolates

Table I. Incidence of pyocin types 1, 3, 5 and 10 of $P$. aeruginosa in isolates from sputum from patients with $\mathrm{CF}$, compared with all isolates from non-CF patients in three Edinburgh hospitals

\begin{tabular}{lcc}
\hline & $\begin{array}{c}\text { Incidence (\%) } \\
\text { of pyocin types } \\
1,3,5 \text { and 10 }\end{array}$ & p value* \\
\hline Source & $28(40)$ & - \\
\hline $\begin{array}{l}\text { Patients with CF } \\
\text { Patients without CF }\end{array}$ & & \\
in hospital 1 & $55(74)$ & $<0.001$ \\
in hospital 2 & $56(70)$ & $<0.001$ \\
in hospital 3 & $88(58)$ & $<0.02$ \\
\hline
\end{tabular}

* Compared with CF isolates. $\left(\chi^{2}=16.69, \mathrm{p}<0.001\right.$ and $\chi^{2}=13.03, \mathrm{p}<0.001$ respectively) whereas isolates from hospital 3 with an incidence of types $1,3,5$ and 10 at $58 \%$ fell midway between the other groups; however, this incidence was still significantly different from that amongst the CF isolates $\left(\chi^{2}=5.95 ; \mathrm{p}<0.02\right.$; table I). Although the isolates from patients attending hospital 3 did not contain any strains from patients with $\mathrm{CF}$, further analysis of the sources of $P$. aeruginosa in hospital 3 showed a large proportion of isolates from sputum samples from patients with pulmonary infections. Sputum isolations of $\boldsymbol{P}$. aeruginosa accounted for $39 \%$ of all isolates from hospital 3 compared with $7 \%$ of isolates from hospitals 1 and 2 . Subsequently, in a retrospective study, when all sputum isolates from hospital 3 were excluded from analysis, the incidence of common pyocin types in non-sputum isolates in hospital 3 was $73 \%$; thus, there was no significant difference in the incidence of common pyocin types in all isolates of $P$. aeruginosa in hospital 1 and 2 and non-sputum isolates in hospital $3\left(\chi^{2}=1 \cdot 38\right.$, $0.5>p>0.1$ and $\chi^{2}=0.23, p>0.5$ respectively). This observation suggested that the relatively low incidence of common types $1,3,5$ and 10 observed in the $\mathrm{CF}$ isolates might also be associated with pulmonary colonisation in non-CF patients. This hypothesis was confirmed when a comparison was made of the incidence of common types in patients with CF and sputum isolates obtained from hospital 3 from post-operative patients and patients with chronic airways disease colonised by $P$. aeruginosa This analysis (table II) indicated no significant difference in the incidence of common pyocin types of $P$. aeruginosa in CF isolates and in isolates from non-CF patients with chronic airways diseases including chronic bronchitis, bronchiectasis, asthma and interstitial lung disease; however, the

Table II. Incidence of pyocin types $1,3,5$ and 10 of $P$. aeruginosa in isolates from sputum from patients with $\mathrm{CF}$ compared with sputum isolates from patients with chronic airways disease (CAD) or post-operative respiratory infection

\begin{tabular}{lcc}
\hline \multicolumn{1}{c}{ Source } & $\begin{array}{c}\text { Incidence }(\%) \\
\text { of pyocin types } \\
1,3,5 \text { and } 10\end{array}$ & p value* \\
\hline $\begin{array}{l}\text { Patients with CF } \\
\text { Patients with CAD }\end{array}$ & $28(40)$ & - \\
$\begin{array}{l}\text { Patients with post-operative } \\
\text { infection }\end{array}$ & $26(44)$ & $<0.50$ \\
\hline
\end{tabular}

* Compared with CF isolates. 
incidence of common pyocin types in acute respiratory infections of post-operative patients was similar to that observed in hospitals 1 and 2.

Detection of the production of low molecular weight S-type pyocins greatly increases the discrimination of pyocin typing. ${ }^{2,3}$ Comparison of the production of S-type pyocin activity in the $\mathrm{CF}$ isolates and those isolates from non-CF patients treated in the three hospitals indicated that there was no significant difference in the proportion of strains producing S-type activity nor in the S-type inhibition patterns observed with the indicator strains.

\section{Discussion}

The evidence from this study indicates that strains of $P$. aeruginosa responsible for pulmonary colonisation in patients with $\mathrm{CF}$ and other chronic airways diseases exhibit an incidence of common pyocin types which is significantly lower than noted in previously published reports from world-wide studies in which the same pyocin typing system was used. In these reports ${ }^{2,9-12}$ the predominance of pyocin types 1, 3, 5 and 10 is clear and ranges from $58 \%$ to $89 \%$ not only amongst clinical isolates, but also amongst non-clinical isolates from food and other environmental sources. ${ }^{10}$ Indeed, the fact that early studies showed that pyocin types $1,3,5$ and 10 accounted for the majority of $P$. aeruginosa isolates on a world-wide basis was the rationale behind our introduction of an additional set of indicator strains ${ }^{13}$ and the suggestion that detection of S-type pyocin activity allowed further subdivision of these common types and hence improved the discriminative potential of pyocin typing to characterise individual isolates of $P$. aeruginosa. ${ }^{2,3}$

The relatively low incidence of common pyocin types in $P$. aeruginosa isolates from infections in patients with CF and other chronic airways diseases suggests that a subpopulation of $P$. aeruginosa, with as yet unidentified colonising factors, might be responsible for pulmonary colonisation in these patients.

Our results cannot be explained as a peculiarity of the Edinburgh CF clinics since the low incidence of types 1, 3, 5 and 10 was also observed in hospital 3 in isolates from non-CF patients with chronic airways diseases. In addition, a preliminary report from a current independent study on the use of pyocin typing to characterise CF isolates of $P$. aeruginosa has confirmed the relatively low incidence of the common pyocin types in another geographical area (T. L. Pitt, personal commurication).
The reasons underlying the predominance of relatively uncommon pyocin types of $P$. aeruginosa in chronic pulmonary colonisation could be associated with factors involved in pyocin production or with the properties of pyocins per se. Bacteriocin production and susceptibility are arguably more commonly observed in strains of $P$. aeruginosa than in most other bacterial species; furthermore, the classes of bacteriocins produced represent the combined range found in other species. Phage-taillike $\mathrm{R}$ and $\mathrm{F}$ pyocins ${ }^{14-16}$ are produced by more than $90 \%$ of clinical isolates and colicin-like, trypsin-sensitive $\mathrm{S}$ pyocins ${ }^{2,17}$ are produced by over $70 \%$ of strains $;^{3}$ susceptibility to these bacteriocins occurs in $100 \%$ of strains. Some strains of $P$. aeruginosa also produce a class of low molecular weight, trypsin-resistant pyocins which resemble the microcins of the enterobacteria. ${ }^{18}$ Little is known of the role of pyocins in vivo or of their cell surface receptors. ${ }^{19}$ From this study, however, we can reasonably conclude that the $S$ pyocins, which share receptors with pseudomonas siderophores, ${ }^{19,20}$ and the microcin-like pyocins, are not involved in pulmonary colonisation.

Alternatively, the apparent predilection of uncommon pyocin types of $P$. aeruginosa to establish chronic pulmonary colonisation might merely indicate a subpopulation of strains with properties, which enhance their ability to establish chronic colonisation, but which are independent of pyocin activity. Since all pyocins (R, F, S and microcinlike) studied to date are encoded by chromosomal genes $^{21,22}$ (findings further confirmed by our own unpublished observations) we could speculate that genes regulating colonising factors might be closely linked or co-regulated with determinants encoding uncommon pyocin type patterns. However, the range of pyocins produced singly or in combinations by strains of $P$. aeruginosa, is considerable and the role of individual pyocins in relation to the type patterns of inhibition against the indicator strains is little understood. It may be significant that the gene responsible for pyocin R2, which is the major pyocin responsible for production of the common type patterns 1 and 10 , is located at $23 \mathrm{~min}$ on the PAO chromosome, near loci regulating several $P$. aeruginosa virulence determinants including exotoxin $\mathrm{A}$ and the siderophore pyoverdin. ${ }^{23} \mathrm{At}$ present, however, there is no evidence which links pyocin genes with genetic determinants for pseudomonas colonising factors.

In conclusion, these studies have demonstrated a subpopulation of $P$. aeruginosa with enhanced potential to establish chronic pulmonary colonisation in patients with $\mathrm{CF}$ and other chronic 
obstructive airways diseases. The basis for this subpopulation is unclear but may include pyocin activity, the genetic determinants for pyocins or other colonising factors. It will be interesting to observe if a similar subpopulation is identified from

\section{REFERENCES}

1. Pitt T L. Epidemiological typing of Pseudomonas aeruginosa. Eur J Clin Microbiol Infect Dis 1988; 7: 238-247.

2. Govan J R W. Pyocin typing of Pseudomonas aeruginosa. In: Bergan T, Norris J R (eds) Methods in Microbiology, vol 10. London, Academic Press. 1978: 61-91.

3. Fyfe J A M, Harris G, Govan J R W. Revised pyocin typing method for Pseudomonas aeruginosa. J Clin Microbiol 1984; $20: 47-50$.

4. Ogle J W, Janda J M, Woods D E, Vasil M L. Characterization and use of a DNA probe as an epidemiological marker for Pseudomonas aeruginosa. $J$ Infect Dis 1987; 155 : 119-126.

5. Grothues D, Koopman U, von der Hardt H, Tummler B. Genome fingerprinting of Pseudomonas aeruginosa indicates colonization of cystic fibrosis siblings with closely related strains. J Clin Microbiol 1988; 26: 19731977.

6. Govan J R W. Alginate biosynthesis and other unusual characteristics associated with the pathogenesis of $P$ seudomonas aeruginosa in cystic fibrosis. In: Donachie W, Griffiths E, Stephen J (eds) Bacterial infections of respiratory and gastrointestinal mucosae. Oxford, IRL Press. 1988: 67-96.

7. Govan J R W. Characteristics of mucoid Pseudomonas aeruginosa in vitro and in vivo. In: Gacesa $\mathrm{P}$, Russell $\mathrm{N}$ $\mathbf{J}$ (eds) Pseudomonas infection and alginates: biochemistry, genetics and pathology. London, Chapman and Hall (in press).

8. Kovacs N. Identification of Pseudomonas pyocyanea by the oxidase reaction. Nature 1956; 178: 703.

9. Gierloff B. Pseudomonas aeruginosa. IV. Pyocin typing of strains isolated from the blue fox (Alopex lagopus), mink (Mustela visor), and dog (Canis familiaris) and from their environment. Nord J Vet Med 1980; 32: 147-160.

10. Nagasawa K, Morishita Y. Pseudomonas aeruginosa and its serologic and pyocin types in commercial perishable foods. Jpn J Med Sci Biol 1983; 36: 59-66.

11. Conroy J V, Baltch A L, Smith R P, Hammer M C, Griffin P E. Bacteremia due to Pseudomonas aeruginosa: use of epidemiological studies with DNA-based typing techniques.

This work was supported by the Scottish Hospitals Endowment Research Trust.

a combined typing system in the eight-year study. $J$ Infect Dis 1983; 148 : 603.

12. Poh C L, Yap E H, Tay L, Bergan T. Plasmid profiles compared with serotyping and pyocin typing for epidemiological surveillance of Pseudomonas aeruginosa. J Med Microbiol 1988; 25: 109-114.

13. Govan J R W, Gillies R R. Further studies in the pyocin typing of Pseudomonas pyocyanea. J Med Microbiol $1969 ; 2: 17-25$.

14. Govan J R W. Studies on the pyocins of Pseudomonas aeruginosa: Morphology and mode of action of contractile pyocins. J Gen Microbiol 1974; 80: 1-15.

15. Govan J R W. Studies on the pyocins of Pseudomonas aeruginosa: Production of contractile and flexuous pyocins in Pseudomonas aeruginosa. J Gen Microbiol 1974; 80: 17-30.

16. Kuroda K, Kagiyama R M. Biochemical relationship among three F-type pyocins, pyocin F1, F2 and F3 and phage KF1. J Biochem 1983; 94: 1429-1441.

17. Ohkawa I, Kageyama M, Egami F. Purification and properties of pyocin S2. J Biochem 1973; 73: 281-289.

18. Baquero F, Moreno F. The microcins. FEMS Microbiol Lett $1984 ; 23: 117-124$

19. Govan J R W. In-vivo significance of bacteriocins and bacteriocin receptors. Scand J Infect Dis 1986; Suppl 49: 31-37.

20. Ohkawa I, Shiga S, Kageyama M. Effect of iron concentration in the growth medium on the sensitivity of Pseudomonas aeruginosa to pyocin S2. J Biochem 1980; 87: 323-331.

21. Shinomiya T, Sano Y, Kikuchi A, Kageyama M. Mapping of pyocin genes on the chromosome of Pseudomonas aeruginosa using plasmid R68.45. In: Mitsuhashi S (ed) Drug resistance in bacteria. Tokyo, Japan Scientific Societies Press; New York, Thieme-Stratton. 1982: 213-217.

22. Sano Y, Kageyama M. Genetic determinant of pyocin AP41 as an insert in the Pseudomonas aeruginosa chromosome. $J$ Bacteriol 1984; 158 : 562-570.

23. Holloway B W, Zhong C. Pseudomonas aeruginosa PAO. In: O'Brien S J (ed) Genetic maps. Ann Arbor, Cold Spring Laboratory. In Press. 